\title{
Fatigue in colorectal cancer patients: prevalence and associated factors
}

\author{
Dálete Delalibera Corrêa de Faria Mota ${ }^{1}$ \\ Cibele Andrucioli de Mattos Pimenta ${ }^{2}$ \\ Ricardo Caponero ${ }^{3}$
}

This study identified the prevalence and predictors of fatigue in colorectal cancer (CRC) patients. Cross-sectional study with 157 adult CRC outpatients (age 60 \pm 11.7 years; $54 \%$ male; cancer stage IV 44.8\%). The Piper Fatigue Scale-revised was used to assess fatigue scores. Socio-demographic, clinical, depression, performance status, pain and sleep disturbance data were assessed. Associations between fatigue and these data were analyzed through logistic regression models. Fatigue was reported by $26.8 \%$ patients. Logistic regression identified three predictors: depression (OR: 4.2; 95\%CI 1.68-10.39), performance status (OR: 3.2; 95\%CI 1.37-7.51) and sleep disturbance (OR: $3.2 ; 95 \%$ CI 1.30-8.09). When all predictors were present, the probability of fatigue occurrence was $80 \%$; when none were present, the probability was $8 \%$. The model's specificity and sensitivity were $81.9 \%$ and $58.6 \%$, respectively. Through the assessment of depression, performance status and sleep disturbance, the probability of fatigue occurrence can be estimated, and preventive and treatment strategies can be rapidly implemented in clinical practice.

Descriptors: Colorectal Neoplasms; Odds Ratio; Regression Analysis; Risk Factors; Signs and Symptoms.

\footnotetext{
${ }^{1}$ PhD, Profesor Adjunto, Faculdade de Enfermagem, Universidade Federal de Goiás, Brasil.

2 PhD, Profesor Titular, Escola de Enfermagem, Universidade de São Paulo, Brasil.

${ }^{3}$ Oncologista, Hospital Santa Helena, São Paulo, Brasil.
}

Corresponding Author:

Dálete Delalibera Corrêa de Faria Mota

Universidade Federal de Goiás. Faculdade de Enfermagem

Rua 227 Qd 68, S/N

Setor Leste Universitário

CEP: 74605-080, Goiânia, GO, Brasil

E-mail: dalete.mota@globo.com 


\section{Fadiga em pacientes com câncer colorretal: prevalência e fatores associados}

Os objetivos deste estudo foram identificar a prevalência e os preditores de fadiga em pacientes com Câncer Colorretal (CCR). Trata-se de estudo seccional com 157 pacientes ambulatoriais com CCR (idade 60 $\pm 11,7$ anos; 54\% homens; estádio câncer IV 44,8\%). A Escala de Fadiga de Piper - Revisada foi utilizada para avaliar fadiga. Dados sociodemográficos, clínicos, depressão, funcionalidade, dor e sono foram avaliados. A associação entre variáveis foi realizada por regressão logística. Fadiga foi reportada por 26,8\% pacientes. Pela regressão logística identificaram-se três preditores: depressão (OR: 4,2; 95\%IC 1,68-10,39), funcionalidade (OR: 3,2; 95\%IC 1,37-7,51) e prejuízo do sono (OR: 3,2; 95\%IC 1,30-8,09). Quando todos preditores estavam presentes, a probabilidade de ocorrência de fadiga foi de $80 \%$; quando nenhum estava presente, a probabilidade foi de $8 \%$. A especificidade e sensibilidade do modelo foram, respectivamente, 81,9 e $58,6 \%$. Conhecendo-se a probabilidade de fadiga, por meio da avaliação de depressão, funcionalidade e prejuízo do sono, torna-se possível a implementação de estratégias de prevenção e tratamento na clínica.

Descritores: Neoplasias Colorretais; Razão de Chances; Análise de Regressão; Fatores de Risco; Sinais e Sintomas.

\section{Fatiga en pacientes con cáncer cuello rectal: superioridad y factores asociados}

Los objetivos de este estudio fueron la identificación de la superioridad y los predictores de fatiga en pacientes con Cáncer Cuello rectal (CCR). Se trata de estudio seccional con 157

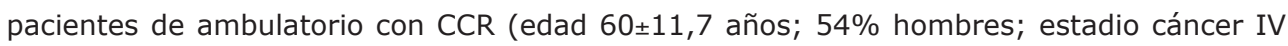
$44,8 \%$ ). La Escala de Fatiga de Piper - Revisada fue utilizada para evaluar fatiga. Datos sociodemográficos, clínicos, depresión, funcionalidad, dolor y sueño fueron evaluados. La asociación entre variables fue realizada por regresión logística. Fatiga fue reportada por $26,8 \%$ pacientes. Por la regresión logística se identificaron tres predictores: depresión (OR: 4,$2 ; 95 \%$ IC 1,68-10,39), funcionalidad (OR: 3,2; 95\%IC 1,37-7,51) y perjuicio del sueño (OR: 3,2; 95\%IC 1,30-8,09). Cuando todos predictores estaban presentes, la probabilidad de ocurrencia de fatiga fue del $80 \%$; cuando ninguno estaba presente, la probabilidad fue del $8 \%$. La especificidad y sensibilidad del modelo fueron, respectivamente, 81,9 y $58,6 \%$. Conociéndose la probabilidad de fatiga, por medio de la evaluación de depresión, funcionalidad y perjuicio del sueño, se vuelve posible la implementación de estrategias de prevención y tratamiento en la clínica.

Descriptores: Neoplasias Colorrectales; Oportunidad Relativa; Análisis de Regresión; Factores de Riesgo; Signos y Síntomas.

\section{Introduction}

For a long time, fatigue in cancer has been studied as an isolated symptom. There were studies that aimed to identify its prevalence, the evolution according to the course of the disease, different treatments for cancer and treatments for fatigue. As these pieces of knowledge seemed relevant, new studies tried to identify the factors that could predict the presence and intensity of fatigue. Studies that investigate the tumor site as a risk factor for fatigue or focus on patients with a single disease site are important for the development of diagnostic strategies and targeted fatigue interventions. Few studies have investigated fatigue in colorectal cancer patients, and none has identified predictors of fatigue in these patients. Thus, aiming to fill this gap, this study was undertaken to identify predictive factors of fatigue in patients with colorectal cancer. 
The prevalence of fatigue is undoubtedly high. In a systematic review that included 27 studies, the prevalence ranged from $4 \%$ to $91 \%$, depending on the cancer population and assessment instruments ${ }^{(1)}$. Specifically in patients under cancer treatment, it ranged from $32 \%$ to $99 \%{ }^{(2)}$. The intensity of the symptom is also considerable, with mean scores ranging from 2.6 to 6.9 , depending on the cancer site and staging(3-4). Fatigue seems to persist even after the "cure" of cancer, since $19 \%$ to $58 \%$ of treated people without evidence of cancer reported the symptom(5-6).

Fatigue is a deleterious symptom that causes suffering, distress, functional limitation and predicts overall survival and quality of life ${ }^{(7-9)}$. Many factors may be related to the occurrence or aggravation of the symptom and recent studies have investigated predictors of cancer-related fatigue in non-specific site groups, such as advanced cancer, outpatients and cancer survivors. It shows that, according to the disease stage, the associated factors may vary. It seems that, in outpatients, the predictors include a reasonable amount of socio-demographic variables (female gender, high education, having a regular job and living without a partner), besides depression and performance status(10-12). On the other hand, fatigueassociated factors in patients with advanced cancer are basically related to other signs and symptoms present in terminally ill patients (e.g. pain, dyspnea, decreased appetite, depression, weakness sensation, anxiety, low hemoglobin levels and others) $)^{(3-4,13-14)}$. Interestingly, among cancer survivors, fatigue predictors include not only performance and symptoms, but also cognitive impairment (stress, coping, self-efficacy) ${ }^{(5)}$.

From the description, a vast variety of physiological, physical, emotional, affective, socio-demographic and treatment-related predictive factors are noted. Yet, it was observed that many studies involved patients with cancer in various sites and that, in those that included patients with different tumors, the tumor site was not a predictive factor. Therefore, this paper specifically focused on colorectal cancer patients' fatigue experience, aiming to investigate its prevalence and independent associated factors.

\section{Methods}

Cross-sectional study, involving 157 Brazilian adults with primary colon or rectal cancer. Inclusion criteria were: age 18 or more, being treated or followed in outpatient oncology services (inpatients were not included). To have or not fatigue was not an inclusion criteria. These subjects composed a convenience sample and were recruited from four outpatient oncology services at Sao Paulo city ( 1 public, 2 private and 1 both), July/2006 to July/2007. The sample representation from each service ranged between $15.3 \%$ and $33.1 \%$. The number of patients that refused to participate was considered low (8 patients).

Oncologists identified the subjects at the participating oncology services. After a medical appointment, the researcher recruited the patients, checked the inclusion criteria and invited them to participate in the study. All participants signed the informed consent term and the ethics committees of each of the institutions involved approved the study. Socio-demographic data and data related to the cancer, its treatment, concomitant medication and clinical signs/symptoms were obtained through interview and medical chart analysis. Pain and sleep disturbance were assessed on a numerical scale (0-10 scale). Performance status (ability to perform daily activities) was assessed using the Karnofsky Performance Status Scale (KPS). Depression was assessed through the Beck Depression Inventory (BDI). It is a self-report instrument that consists of 21 items to evaluate depressive symptoms. Each item is scored from 0 to 3 and the total BDI score varies between 0 and 63 . Scores between 16 and 20 account for dysphoria and above 21 for depression(15). In the current study, Cronbach's alpha equaled 0.83 .

The Piper Fatigue Scale (PFS) - revised is a 22-item self-report instrument with three dimensions (behavioral, affective and sensorial/psychological). Each item is scored on a numerical scale (0-10). The dimension scores and total score vary between 0 and 10 and are obtained by adding up the score of each item and dividing this by the number of items on each dimension, or by 22 when calculating the total score. This instrument was validated for use in Brazilian cancer patients and the internal consistencies for the total scale (Cronbach's alpha $=0.94$ ) and its dimensions (Cronbach's alpha between 0.84 and 0.94 ) were very good in this study sample(16). The correlation between fatigue intensity on the numerical scale ( 0 to 10 ) and the Piper Fatigue Scale-revised ( 0 to 10 ) was also very good (Pearson $r=0.748 ; p<0.001$ ). Fatigue was analyzed as a nominal variable and the cut-off point was established at score 4 ( $<4=$ no fatigue; $\geq 4=$ with fatigue), based on the consensus of the National Comprehensive Cancer Network $(2007)^{(17)}$ and on the percentile distribution of the Piper scores, based on the present study findings.

When the subjects finished answering the self-report instruments, the researcher checked for missing data and, in case data were missing, the researcher handed the items back to the subjects so they could complete the instrument. Nevertheless, missing data occurred. On the $\mathrm{BDI}$, a total of two items were blank and the mean score 
of that item all other subjects had answered was used to replace the missing data. On the PFS, three items were blank and the patient's mean subscale score of all items in the same dimension was used to replace the missing data. Missing socio-demographic, clinical, treatment data were left blank.

For univariate analysis, Chi-Square test, Likelihood Ratio, Mann-Whitney test or T-Test were done. The variables that were associated to fatigue were inserted in the logistic regression model. The quantitative variables were analyzed through ROC curves to establish cut-off scores based on these study findings, and they were pain (cut-off score=6.0), sleep disturbance (cut-off score=5.0), performance status (cut-off score $=80 \%$ ), and depression (cut-off score=13). The variables were inserted in the logistic regression model, using forward stepwise. The Statistical Package for the Social Sciences-version 15.0 was used to perform the analyses and $p<0.05$ was preset for statistical significance.

\section{Results}

Socio-demographic, clinical, disease and treatment characteristics

There was a slight predominance of men $(n=85$; $54.1 \%)$, married $(n=107 ; 68.2 \%)$ and white $(n=102$; $65.0 \%$ ). Most subjects were middle-aged adults (41-64 years), and the mean age was $60.0( \pm 11.7)$, varying from 28 to 84. In terms of formal education, over half of the participants studied over 9 years $(n=102 ; 65.0 \%)$. Most of them were not employed $(n=112 ; 71.3 \%)$ and $113(72.0 \%)$ were being assisted in private oncology clinics. The clinical characterization of the participants is presented in Table 1.

Table 1- Patients' clinical characteristics

\begin{tabular}{|c|c|c|}
\hline & \multicolumn{2}{|c|}{ Patients } \\
\hline & $\mathrm{N}$ & $\%$ \\
\hline \multicolumn{3}{|l|}{ BMI $(n=151)$} \\
\hline Underweight $(<18.5)$ & 3 & 2.0 \\
\hline Normal $(18.5-24.9)$ & 64 & 42.4 \\
\hline Overweight (25.0-29.9) & 63 & 41.7 \\
\hline Obese (30.0-39.9) & 21 & 13.9 \\
\hline Mean (SD); median; min-max & \multicolumn{2}{|c|}{$25.5( \pm 4.0) ; 25.6 ; 13.6-36.3$} \\
\hline \multicolumn{3}{|l|}{ Hemoglobin level $(n=124)$} \\
\hline No anemia & 88 & 71.0 \\
\hline Mean (SD); median; min-max & \multicolumn{2}{|c|}{$13.1( \pm 1.7) ; 13.1 ; 9.8-17.0$} \\
\hline \multicolumn{3}{|l|}{ Co-morbidities ( $n=157$ ) } \\
\hline Yes & 87 & 55.4 \\
\hline \multicolumn{3}{|l|}{ Medication ( $n=157$ ) } \\
\hline Yes & 120 & 76.4 \\
\hline
\end{tabular}

Table 1 - (continuation)

\begin{tabular}{|c|c|c|}
\hline & \multicolumn{2}{|c|}{ Patients } \\
\hline & $\mathrm{N}$ & $\%$ \\
\hline - Anxiolytics & 16 & 13.3 \\
\hline - Antidepressants & 16 & 13.3 \\
\hline \multicolumn{3}{|l|}{ Colostomy (n=155) } \\
\hline No & 99 & 63.9 \\
\hline \multicolumn{3}{|l|}{ Clinical staging $(n=134)$} \\
\hline 1 & 12 & 9.0 \\
\hline II & 29 & 21.6 \\
\hline III & 33 & 24.6 \\
\hline IV & 60 & 44.8 \\
\hline \multicolumn{3}{|l|}{ Present treatment for cancer $(n=157)$} \\
\hline Not undergoing treatment & 54 & 34.4 \\
\hline Receiving treatment & 103 & 65.6 \\
\hline - Chemo and/or radiotherapy & 99 & 96.1 \\
\hline $\begin{array}{l}\text { - Other treatments (hormone, } \\
\text { bisphosphonate, etc) }\end{array}$ & 4 & 3.9 \\
\hline \multicolumn{3}{|l|}{ Surgery $(n=156)$} \\
\hline Undergone surgery $(n=148)$ & 148 & 94.9 \\
\hline $\begin{array}{l}\text { Mean time in months since surgery } \\
\text { (SD); median; min-max }\end{array}$ & $23.5( \pm$ & $0 ; 1-240$ \\
\hline \multicolumn{3}{|l|}{ Performance Status $(n=153)$} \\
\hline Mean (SD); median; min-max & $86.7( \pm 1$ & $0 ; 50-100$ \\
\hline \multicolumn{3}{|l|}{ Presence of pain $(n=157)$} \\
\hline Yes & 55 & 35.0 \\
\hline Mean (SD); median; min-max & $4.6(=$ & ; $1-10$ \\
\hline \multicolumn{3}{|l|}{ Sleep Disturbance $(n=156)$} \\
\hline Yes & 60 & 38.5 \\
\hline Mean (SD); median; min-max & $5.9(=$ & ; $1-10$ \\
\hline \multicolumn{3}{|l|}{ Depression $(n=156)$} \\
\hline Mean (SD); median; min-max & 9.3( & ; 0-37 \\
\hline
\end{tabular}

In Table 1, a significant portion of subjects with altered BMI (57.6\%) can be observed. Of 157 subjects, 110 (70.1\%) had colon tumors (data not shown in Table), and the others had rectal cancer. Many of the subjects had advanced stage disease (III and IV) and almost all received chemotherapy and/or radiotherapy. Nearly half of the patients (55\%) had co-morbidities and 20\% used antidepressants and/or anxiolytics. Scores compatible with dysphoria and depression were present in $15.4 \%$ of the subjects.

\section{Prevalence of fatigue}

Almost half of the patients $(n=78 ; 49.7 \%)$ reported no fatigue at all (zero score). Mild, moderate and severe fatigue was reported by $37(23.5 \%), 35(22.4 \%)$ and 7 $(4.4 \%)$ patients, respectively. Considering that clinically significant fatigue was present when the total PFS score $\geq 4,26.8 \% \quad(n=42)$ of the patients reported fatigue. Among those who reported fatigue, the mean score was $5.8(\mathrm{SD}=1.3)$, the median 5.4 and the minimum and maximum scores 4.2 and 9.6 . 


\section{Associated and predictive factors}

In univariate analysis, fatigue showed association with five out of twenty investigated variables: to be assisted at a public hospital, pain, sleep disturbance, depression and performance status. These five variables were included in the multiple regression model (Table 2) and three independent predictors for fatigue were identified: sleep disturbance, depression and performance status. The risk for fatigue was higher for depression $(O R=4.2)$ than for sleep disturbance $(O R=3.2)$ and performance status $(\mathrm{OR}=3.2)$.

Table 2- Logistic regression model for fatigue $(n=151)$

\begin{tabular}{|c|c|c|c|c|c|c|}
\hline Variable & Estimated error $(\beta)$ & Standard error & Odds Ratio & \multicolumn{2}{|c|}{$95 \% \mathrm{Cl}$} & $\mathbf{P}$ \\
\hline \multicolumn{7}{|l|}{ Private (0) x Public (1) } \\
\hline Pain & & & & & & 0.302 \\
\hline \multicolumn{7}{|l|}{ No $(0) \times$ Yes (1) } \\
\hline Pain & & & & & & 0.093 \\
\hline \multicolumn{7}{|l|}{ Score $<6(0) \times$ Score $\geq 6(1)$} \\
\hline Sleep disturbance & & & & & & 0.964 \\
\hline \multicolumn{7}{|l|}{ No $(0) \times$ Yes $(1)$} \\
\hline Sleep disturbance & 1.176 & 0.467 & 3.241 & 1.299 & 8.087 & 0.012 \\
\hline \multicolumn{7}{|l|}{ Score $<5(0) \times$ Score $\geq 5(1)$} \\
\hline Depression & & & & & & 0.670 \\
\hline W/O depression(0) $x$ Dysphoria(1) & & & & & & 0.543 \\
\hline x Depression (2) & & & & & & 0.868 \\
\hline Depression & 1.430 & 0.465 & 4.180 & 1.681 & 10.393 & 0.002 \\
\hline \multicolumn{7}{|l|}{ Score $<13(0) \times$ Score $\geq 13(1)$} \\
\hline Performance status & 1.167 & 0.433 & 3.212 & 1.373 & 7.511 & 0.006 \\
\hline Score $>80 \%(0) \times$ Score $<80 \%(1)$ & & & & & & \\
\hline
\end{tabular}

(1) Reference category

Utilizing the estimated error for each of the independent predictive variables, the Fatigue Prediction Table (Table 3 ) could be constructed. This Table shows the probability of the individual to have fatigue based on the presence/absence of each variable. Patients who do not have any of these predictors have approximately $8 \%$ chance of having fatigue and those with the three independent predictors have approximately $80 \%$ chance. It is observed that not only the number of factors, but also their nature influences the likelihood of having fatigue. Depression increases the likelihood of having fatigue more than the other factors (Table 3 ).

Table 3 - Fatigue Prediction Table: probability of fatigue occurrence in the presence of independent predictive factors*

\begin{tabular}{cccc}
\hline $\begin{array}{c}\text { Sleep } \\
\text { Disturbance }\end{array}$ & $\begin{array}{c}\text { Performance } \\
\text { status }\end{array}$ & Depression & $\begin{array}{c}\text { Probability of Fatigue } \\
\text { occurrence }\end{array}$ \\
\hline 0 & 0 & 0 & 0.082489 \\
1 & 0 & 0 & 0.224088 \\
0 & 1 & 0 & 0.225308 \\
0 & 0 & 1 & 0.271307 \\
1 & 1 & 0 & 0.483007 \\
1 & 0 & 1 & 0.544631 \\
0 & 1 & 1 & 0.546366 \\
1 & 1 & 1 & 0.79462 \\
\hline
\end{tabular}

$*_{0}=$ no; $1=$ Yes
The sensitivity of the model identified in this study was $58.6 \%$. The specificity level equaled $81.9 \%$. These data indicate that, by using the Fatigue Prediction Table, constructed in this study, the chance to correctly identify a fatigued person is approximately $60 \%$, against approximately $82 \%$ to correctly identify a person who is not fatigued.

\section{Discussion}

The identification of fatigue predictors permits the prevention, early diagnosis and development of specific actions for its control. Little was known on the prevalence of fatigue in colorectal cancer patients and there were no studies on fatigue predictors in this population, which was achieved in this search.

In general, the study sample is similar to other studies on colorectal cancer patients concerning sociodemographic, clinical and treatment data(18-19). The data was collected at four oncology services with different characteristics (public and private, hospitals and outpatient clinics) and this improved the representation of patients with colorectal cancer. Although a randomization of the sample was desirable, that was not feasible. Thus, the option of using four different oncology services increased external validity. 
The cut-off score of 4 or higher, which refers to the percentile 25 of the fatigue score distribution and meets National Comprehensive Cancer Network criteria(17), represents the fatigue present in $75 \%$ of the sample. In the literature review, it was noted that other authors also adopted the same cut-off score ${ }^{(20)}$, which is beneficial to standardize and compare assessments. In addition, having fatigue cut-off scores higher than 1, 2 or 3 contributes to assuring that fatigue has clinical relevance, which may not occur with lower cut-off scores related to minimum discomfort.

No studies on fatigue predictors in colorectal cancer patients were found, but the study data on fatigue prevalence and intensity were similar to those used in this $\operatorname{search}^{(18-19,21)}$. When fatigue prevalence $(26.8 \%)$ and intensity (mean=5.8; SD=1.3; median=5.4) in this research were compared to studies involving other cancer patients, it was noted that fatigue was less frequent than in studies on patients in palliative care and receiving adjuvant chemotherapy or radiotherapy(1-2), and higher than some cancer survivors' experience, who reported $26 \%^{(8)}$. A slightly higher prevalence of fatigue $(33 \%)$, using the same cut-off score as this study, was observed among colorrectal cancer patients in the United Kingdom(22). This higher prevalence might be due to the instrument used for fatigue assessment. In a Turkish study that proposed an intervention for cancer-related fatigue among intervention group patients undergoing chemotherapy, the baseline fatigue score assessed through the Piper Fatigue Scale was $3.5^{(23)}$. These researchers probably included scores from all patients, lowering the mean score when compared to the present study.

The univariate and multivariate analysis identified the risk and predictive fatigue factors. The only sociodemographic risk factor was the "public health service". No study was found that analyzed the relationship between fatigue and health service, probably because the majority of published studies include subjects who live in developed countries, where the quality of health services is similar, independently of the provider.

Pain, sleep disturbance and depression were risk factors for fatigue. The mean scores of these symptoms among fatigued patients were higher than among nonfatigued patients. In the same manner, performance status was worse among fatigued than among nonfatigued subjects. Various studies in different scenarios also identified performance status, pain, depression and sleep alteration, among others, as factors related to fatigue ${ }^{(4,6,11,14)}$.

The discussion on the relation between fatigue and depression should be raised. Studies have attempted to identify cause-effect relations between these symptoms, but no conclusion has been reached. What is clear is that there is a positive and moderate/ strong correlation between them and that the rate of comorbidity fatigue/depression is harmful. Yet, some may consider the assessment of depression in cancer patients through the BDI as doubtful, due to the number of items that investigate somatic issues, which might cause confusion between depression and cancer symptoms. But this instrument was chosen because of its wide acceptance and utilization in cancer research.

The variables gender, age, marital status, skin color, education, employment status, family income, clinical cancer site, medical treatments, body mass index, level of hemoglobin, presence of illnesses in co-morbidities, use of antidepressants or anti-anxiety drugs and colostomy did not relate to fatigue. There are studies that observed some of these variables as risk factors for fatigue, such as female gender(18), young age ${ }^{(2,19)}$, the absence of regular job(5), cancer treatment ${ }^{(2)}$, among others. In other studies, other variables were also not observed, such as cancer staging, presence of some co-morbidities, concomitant medications, etc. ${ }^{(4,24)}$.

The greater or minor likelihood of a factor to predict an outcome (fatigue) can be calculated using logistic regression. Thus, by evaluating sleep, depression and performance status, the probability of the patient having fatigue can be observed in the Fatigue Predictors Table (Table 3). If the three predictive factors are present (sleep disturbance, depression and performance status), the chance a patient has fatigue is approximately $80 \%$, and if none is present, the probability of fatigue occurrence is only $8 \%$. No study that presented the probability of fatigue could be found. The fact that only three variables were able to predict fatigue so accurately ( $80 \%$ ) drew our attention and indicated that the model proposed in this paper is very useful to identify fatigue. Yet, there is still a need to investigate the factors that predict the fatigue of the other $20 \%$ of the patients.

The specificity of the model was good $(81.9 \%)$, but the sensitivity of the model was moderate (58.6\%), increasing chances of not diagnosing a fatigued patient. New studies are necessary, which attempt to identify other risk factors that increase the sensitivity of the model. No study with logistic regressions for the predictive factors identifying fatigue in patients with rectal cancer was found and, among the three studies that used the logistic regression method involving 
patients with other tumors, only one mentioned the discriminatory capacity of the model $=0.88^{(3)}$. In that study, conducted with men with cancers in several sites, the predictors were sadness, dizziness, pain, appetite loss, irritability and dyspnea(3).

The risk factors "public health service" and pain were excluded from the logistic regression models. Not every risk factor is a predictive factor, because regression analysis distinguishes those that are important for an outcome occurrence (fatigue), in an independent way, from those that seem to be important for the phenomenon, but which in fact are surrogate to others.

The findings of this search raised some issues: 1 ) If the sleep disturbance, the presence of depression and injury in performance status indicate the likelihood of a patient with colorectal cancer to have fatigue and if, 2) in oncology patients' consultations, their sleep, depressive symptoms and functionality are quite often evaluated, it raises questions on the real need of using multidimensional scales, such as the Piper Fatigue Scale - revised, to diagnose fatigue.

Based on the sleep, depression and performance status assessment results, the professional may, in fact, estimate the probability of the patient havinh fatigue or not, with high specificity (81.9\%). However, in view of the model's moderate sensitivity (58.6\%), which increases the chance of a false negative, a strategy to deal with this situation is necessary.

The use of a numerical scale for the evaluation of fatigue may be an alternative to the long instruments that exist to confirm the presence and severity of fatigue. It has the advantage of being fast and feasible, reducing the barriers for symptom assessment and streamlining the diagnosis in care and research. In this study, the correlation between the numerical fatigue scale and the Piper Fatigue Scale - revised was tested and a high correlation $(r=0.748 ; p<0.001)$ was noted, which indicates that it can be useful on a daily base during care delivery to cancer patients. The main limitation of the numerical scale is the lack of details about the symptom, which could be obtained with the help of multidimensional instruments.

Some limitations of this study can be appointed. The study was cross-sectional and the sample was not randomized; the way the variable "cancer treatment" was dichotomized - receiving adjuvant chemotherapy or radiotherapy or not - might have covered some difference between individuals receiving specific anticancer treatments; and there was no investigation on gastrointestinal symptoms (e.g. diarrhea, constipation).
The inclusion of patients using concomitant medications, such as antidepressants and anti-anxiety medications, may be questioned, since these may influence the presence and intensity of fatigue. Still, the inclusion of inpatients with colorectal cancer is desirable, considering that the results of the predictors and risk factors might be broader in this population. Such limitations need to be overcome in future studies. Despite these limitations, the researchers believe that the results can be generalized to other Brazilian or nonBrazilian cancer patients, as the patients included in this study showed a profile similar to patients included in other international studies. The identification of fatigue predictors in colorectal cancer outpatients from other countries could help to validate the findings of this study. Yet, future research might as well test the Fatigue Prediction Table. A cohort study would be the ideal method to validate the findings of this search and improve the fatigue diagnostic strategies in clinical practice.

Based on this study, some progress can be pointed out and the implications for the practice are diverse. The first nursing publication about fatigue in Brazil was on laryngeal cancer(25). Now, for the first time in our country, the prevalence of fatigue was determined in patients with colorectal cancer, and a cut-off score for fatigue diagnosis was established. In an international scope, some results are innovative, as the independent fatigue predictors were not known in outpatients with colorectal cancer. This study presents the Fatigue Prediction Table, which permits investigating the probability of fatigue occurrence and contributes to symptom control. Sleep disturbance, depression and poor performance status together predicted $80 \%$ of fatigue cases in colorectal cancer situations, which is very good. Depression increased the risk of fatigue by four times, and sleep disturbance and performance status by three times. Due to the moderate sensitivity result of the model ( $58 \%)$, there is a considerable chance of having false negatives, which perhaps can be minimized by using a numerical scale from 0 to 10 , in which score $\leq 4$ indicates fatigue.

\section{Conclusions}

The prevalence of fatigue among colorectal cancer patients was $26.8 \%$. Fatigue predictors were sleep disturbance, depression and performance status. When all factors were present, the chance a patient had fatigue was $80 \%$, which indicated good prediction. When all factors were absent, the chance a patient had 
fatigue was $8 \%$. Depression increased the risk of fatigue fourfold, and sleep disturbance and performance status threefold. The specificity of the prediction model was very good, and the sensitivity was moderate.

\section{References}

1. Lawrence DP, Kupelnick B, Miller K, Devine D, Lau J. Evidence report on the occurrence, assessment, and treatment of fatigue in cancer patients. JNCI Monographs. 2004;32:40-50.

2. de Jong N, Courtens AM, Abu-Saad HH, Schouten HC. Fatigue in patients with breast cancer receiving adjuvant chemotherapy: a review of the literature. Cancer Nurs. 2002;25(4):283-97.

3. Hwang SS, Chang VT, Rue M, Kasimis B. Multidimensional independent predictors of cancer-related fatigue. J Pain Symptom Manage. 2003;26(1):604-14.

4. Wang XS, Giralt SA, Mendoza TR, Engstrom MC, Johnson BA, Peterson N, et al. Clinical factors associated with cancer-related fatigue in patients being treated for leukemia and non-Hodgkin's Lymphoma. J Clin Oncol. 2002;20(5):1319-28.

5. Young KE, White CA. The prevalence and moderators of fatigue in people who have been successfully treated for cancer. J Psychosom Res. 2006;60:29-38.

6. Servaes P, Verhagen S, Schreuder B, Veth RP, Bleijenbert G. Fatigue after treatment for malignant and benign bone and soft tissue tumors. J Pain Symptom Manage. 2003;26(6):1113-22.

7. Llobera J, Esteva M, Rifá J, Benito E, Terrasa J, Rojas C, et al. Terminal cancer: duration and prediction of survival time. Eur J Cancer. 2000;36:2036-43.

8. Groenvold M, Petersen MA, Idler E, Bjorner JB, Fayers PM, Mouridsen HT. Psychological distress and fatigue predicted recurrence and survival in primary breast cancer patients. Breast Cancer Res Treat. 2007;105(2):209-19.

9. Dagnelie PC, Pijls-Johannesma MCG, Lambin P, Beijer S, De Ruysscher D, Kempen GI. Impact of fatigue on overall quality of life in lung and breast cancer patients selected for high-dose radiotherapy. Ann Oncol. 2007;18:940-4.

10. Akechi T, Kugaya A, Okamura H, Yamawaki S, Uchitomi Y. Fatigue and its associated factors in ambulatory cancer patients: a preliminary study. J Pain Symptom Manage. $1999 ; 17(1): 42-8$.

11. Dimeo F, Schmittel A, Fietz T, Schwartz S, Kohler $P$, Boning $D$, et al. Physical performance, depression, immune status and fatigue in patients with hematological malignancies after treatment. Ann Oncol. 2004;15: 1237-42.
12. Ahlberg K, Ekman T, Gaston-Johansson F. Fatigue, psycholocial distress, coping resources, and functional status during radiotherapy for uterine cancer. Oncol Nurs Forum. 2005;32(3):633-40.

13. Echteld MA, Passchier J, Teunissen S, Claessen S, de Wit R, van der Rijt CC. Multidimensional fatigue and its correlates in hospitalised advanced cancer patients. Eu J Cancer. 2007;43:1030-6.

14. Brown DJF, McMillan DC, Milroy R. The correlation between fatigue, physical function, the systemic inflammatory response, and psychological distress in patients with advanced lung cancer. Cancer. 2005; 103(2):377-82.

15. Gorentein C, Andrade L. Validation of a Portuguese version of the Beck Depression Inventory and the StateTrait Anxiety Inventory in Brazilian subjects. Braz J Med Biol Res.1996;29:453-7.

16. Mota DDCF, Pimenta CAM, Piper BF. Fatigue in Brazilian cancer patients, caregivers, and nursing students: a psychometric validation study of the Piper Fatigue Scale - Revised. Support Care Cancer. 2009;17(6):645-52.

17. National Comprehensive Cancer Network (NCCN). [Internet]. Cancer-related fatigue: NCCN Clinical Practice Guidelines in Oncology. [acesso 29 março 2011]. Disponível em: http://www.nccn.org/professionals/ physician_gls/pdf/fatigue.pdf

18. Schmidt CE, Bestmann B, Kuchler $T$, Longo WE, Kremer B. Ten-year historic cohort of quality of life and sexuality in patients with rectal cancer. Dis Colon Rectum. 2005;48:483-92.

19. Arndt V, Merx H, Stegmaier C, Ziegler H, Brenner $\mathrm{H}$. Quality of life in patients with colorectal cancer 1 year after diagnosis compared with the general population: a population-based study. J Clin Oncol. 2004;22(23):4829-36.

20. Chang YJ, Lee JS, Lee CG, Lee Ws, Lee KS, Bang $\mathrm{SM}$, et al. Assessment of clinical relevant fatigue level in cancer. Support Care Cancer. 2007;15:891-6.

21. Galloway SC, Graydon JE. Uncertainty, symptom distress, and information needs after surgery for cancer of the colon. Cancer Nurs. 1996;19(2):112-7.

22. Storey, DJ, Waters RA, Hibberd CJ, Rush RW, Cargill AT, Wall LR, et al. Clinically relevant fatigue in cancer outpatients: the Edinburgh Cancer Centre symptom study. Ann Oncol. 2007;18:1861-9.

23. Yeşilbalkan OU, Karadakovan A, Göker E. The Effectiveness of Nursing Education as an Intervention to Decrease Fatigue in Turkish Patients Receiving Chemotherapy. Oncol Nurs Forum. 2009;36(4):E215-22. 
24. Ness RM, Holmes A, Klein R, Greene J, Dittus R. Outcome states of colorectal cancer: identification and description using patient focus group. Am J Gastroenterol. 1998;93(9):1491-7.

25. Coelho FMR, Sawada NO. A fadiga nos pacientes com câncer de laringe. Rev. Latino-Am. Enfermagem. $1999 ; 7(5): 103-8$. 